\title{
STABILITY FORMULA FOR TETRAPOD INCORPORATING SLOPE EFFECT ${ }^{1}$
}

\author{
Kyung-Duck Suh ${ }^{2}$ and Jin-Sung Kang ${ }^{3}$
}

To develop a stability formula for Tetrapods armoring rubble mound breakwaters, sixty hydraulic model tests have been conducted for various wave conditions and slope angles of breakwaters. The test results are used, along with the data of previous researchers, to develop a new stability formula. The developed formula is proven to be applicable to breakwaters with various slope angles with reasonable accuracy. It is also shown to be applicable to low-crested breakwaters and different packing densities, if the corresponding terms are incorporated in the formula. The uncertainty of the proposed formula is also given.

Keywords: armor units; breakwaters; hydraulic models; model tests; stability; Tetrapods

\section{INTRODUCTION}

A rubble mound breakwater is the most primitive but still-widely-used breakwater, and Tetrapod is one of the armor units that are widely used all over the world. Hudson (1959) proposed a stability formula for Tetrapods based on the results of small-scale model tests using regular waves. Van der Meer (1988) proposed a formula using irregular wave test results for surging waves. A similar type of formula was proposed by De Jong (1996) for plunging waves, which contains additional terms that take into account the influence of crest elevation and packing density. Later Van der Meer (2000) recommended using these formulas as a set of formulas that intersect at the point of minimum stability. The formulas of Van der Meer (1988) and De Jong (1996) include the effects of wave period, storm duration, and damage level, which were not included in the Hudson's (1959) formula. On the other hand, Hanzawa et al. (1996) proposed a formula similar to Van der Meer (1988) for a horizontally composite breakwater, i.e. a caisson breakwater covered with Tetrapods on its seaside.

The formulas of Van der Meer (1988) and De Jong (1996) have restrictions that they can only be used for the structure slope of 1:1.5. In this study, we develop a formula which can be used for various structure slopes based on hydraulic model test results of the present and previous studies. In the following section, the hydraulic model tests are described, the results of which are used for the derivation of the stability formula in the next section. The developed formula is then compared with the present and other researchers' test results, and its accuracy and uncertainty are examined. Finally major conclusions are given.

\section{HYDRAULIC MODEL TESTS}

Tests were carried out in the wave flume at the Hydraulic and Coastal Engineering Laboratory of Seoul National University. Fig. 1 shows the arrangement of the model breakwater and wave gauges. The flume was 36-m long, 1.0-m wide, and 1.2-m deep. It was equipped with a piston-type wave generator at one end, and a quarter-ellipse-shape wave absorber at the other. A horizontal bed with a $1 / 25$ foreshore slope was installed at the elevation of $20 \mathrm{~cm}$ from the bottom of the flume. The breakwater model was placed at a distance of $25 \mathrm{~m}$ from the wave maker and a few centimeters from the beginning of the horizontal bed. The test section was divided into two channels by a vertical wall along the wave flume, each having a width of $0.6 \mathrm{~m}$ and $0.4 \mathrm{~m}$, respectively. The breakwater was installed in the wider channel and the other channel was left empty. To measure the incident waves, three wave gauges were installed in the empty channel. The free surface displacements measured by these wave gauges were used to separate the incident and reflected waves using the method of Suh et al. (2001). Even though the channel is empty, wave reflection occurs from the sloping bed and wave absorber. Waves were generated at a water depth of $0.6 \mathrm{~m}$ and the water depth at the structure was 0.4 $\mathrm{m}$.

Tetrapods were used for the armor layer, the main characteristics of which were: height $H_{T}=6.2$ $\mathrm{cm}$; nominal size $D_{n}=4.03 \mathrm{~cm}$; mass density $\rho_{a}=2.3 \mathrm{gr} / \mathrm{cm}^{3}$; weight $W=150.5 \mathrm{gr}$; and layer thickness $8.0 \mathrm{~cm}$. The underlayer consisted of stones of nominal size $D_{n 50}=2.0-2.5 \mathrm{~cm}$ and thickness of $6.0 \mathrm{~cm}$, while the core consisted of stones of nominal size $D_{n 50}=1.3 \mathrm{~cm}$. Three different

\footnotetext{
${ }^{1}$ This paper is an extended version of the technical note 'Stability formula for Tetrapods' published in Journal of Waterway, Port, Coastal, and Ocean Engineering, 138(3), 261-266 (2012).

${ }^{2}$ Department of Civil and Environmental Engineering, Seoul National University, 1 Gwanak-ro, Gwanak-gu, Seoul 151-744, Republic of Korea. kdsuh@snu.ac.kr

${ }^{3}$ Civil Division, POSCO E\&C, 36 Songdo-dong, Yeonsu-gu, Incheon 406-732, Republic of Korea. jsriver@poscoenc.com
} 
slopes of structure were tested, i.e. $\cot \theta=1.33,1.5$, and 2.0 , where $\theta=$ angle of structure slope measured from horizontal. Fig. 2 shows the cross-section of the breakwater of slope of $1: 1.5$, which is similar to that used in the test of Van der Meer (1988). A little wave overtopping occurred when the significant wave height was greater than $18 \mathrm{~cm}$. Tetrapods were placed in two layers. The upper layer Tetrapods were placed randomly on the regularly placed lower layer. Since the Tetrapods in contact with the sidewalls of the flume have less degree of interlocking, they were fixed not to move and were not included in the calculation of damage. For $\cot \theta=1.33,1.5$, and 2.0, the numbers of Tetrapods were 380,399 , and 456 , and the slope areas were $0.585,0.609$, and $0.709 \mathrm{~m}^{2}$, respectively, so that the packing density was 1.05 .

In order to cover both plunging and surging waves, the wave steepness varied between 0.012 and 0.056. Four different mean wave periods were applied: $T_{z}=1.36,1.67,2.10$, and $2.45 \mathrm{~s}$. For each wave period, five different significant wave heights ranging from 9 to $19 \mathrm{~cm}$ were used. Therefore, 20 tests were conducted for each different slope angle, which resulted in a total of 60 tests.

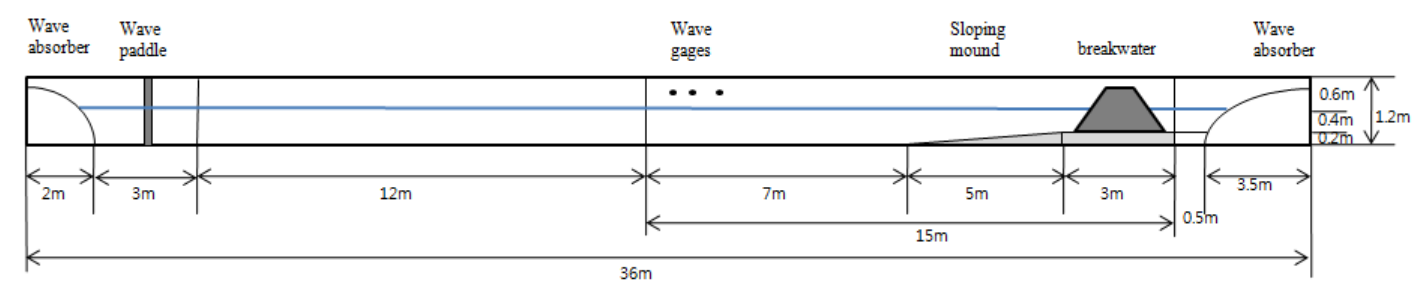

$<$ Side view $>$

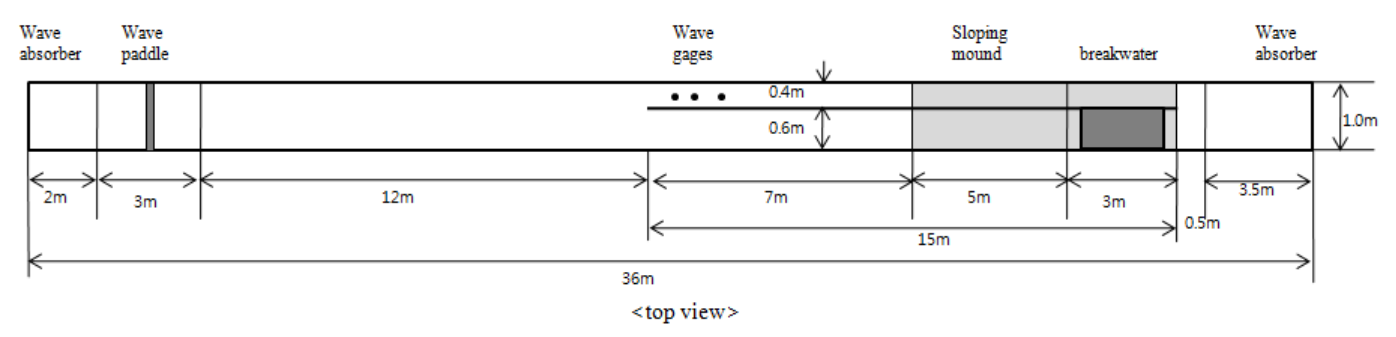

Figure 1. Sketch of wave flume and experimental setup.

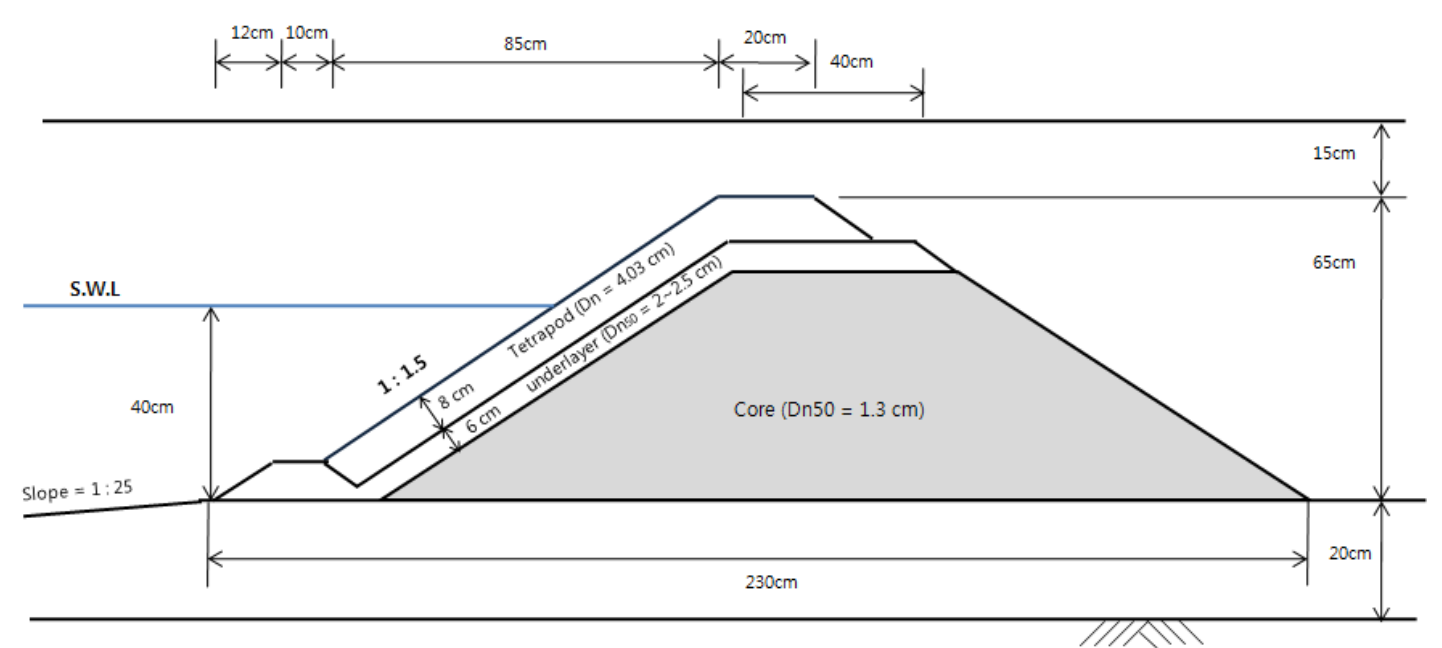

Figure 2. Cross-section of breakwater (slope=1:1.5). 
The wave measurement was made during the test on the flat bottom before the sloping beach as shown in Fig. 1. However, we have to know the wave height at the toe of the breakwater. In order to obtain the relationship between the wave heights at the two places, wave measurements were made there before the breakwater was installed. A linear relationship was obtained between the wave heights for each wave period. This relationship was used in the conversion of the measured wave height on the flat bottom to that at the toe of the breakwater.

The modified Bretschneider-Mitsuyasu spectrum (Goda 2000) was used, which is equivalent to the Pierson-Moskowitz spectrum:

$$
S(f)=0.205 H_{s}^{2} T_{s}^{-4} f^{-5} \exp \left[-0.75\left(T_{s} f\right)^{-4}\right]
$$

where $S(f)$ = wave spectral density function; $f=$ frequency; $H_{s}=$ significant wave height; and $T_{s}=$ significant wave period. The mean wave period was calculated by using the relationship $T_{z}=T_{s} / 1.2$.

Each complete test consists of a short generation of small waves for stabilizing the Tetrapods, a test of 1000 waves, an intermediate photographing, a test of 2000 more waves, and a final photographing. The location and time of the displacing Tetrapods were observed by eyes during the test. A Tetrapod was regarded to be displaced when it moved more than one diameter, when it came back to its position after short displacement, or when it rotated more than $180^{\circ}$. After each complete test the armor layer was removed and rebuilt.

\section{DERIVATION OF STABILITY FORMULA}

The test results are summarized in Table 1, in which $N_{0}=$ relative damage which is the number of displaced armor units in a width (along the longitudinal axis of the breakwater) of one nominal size; and $N=$ number of waves. The significant wave height and period were calculated by applying the zero-crossing method to the incident wave profile obtained from the wave separation.

The derivation of stability formula closely follows the procedure described in Van der Meer (1987a). First, by using the data in Table 1, damage curves are drawn for each wave period and storm duration (i.e. number of waves). An example of such damage curves is shown in Fig. 3. From these damage curves, the values of $H_{s} / \Delta D_{n}$ are taken for $N_{0}$ of $0,0.5$, and 1.5, and the corresponding surf similarity parameters are calculated. Here $\Delta=\rho_{a} / \rho_{w}-1$ is the relative mass density, and $\rho_{w}$ is the mass density of water. The surf similarity parameter is given by $\xi_{z}=\tan \theta / \sqrt{S_{z}}$, in which $S_{z}=H_{s} / L_{0}$ and $L_{0}=g T_{z}^{2} /(2 \pi)$. The data set is augmented with the data of Van der Meer (1987b) and De Jong (1996) of the similar crest elevation and packing density to the present test. Fig. 4 shows the influence of the surf similarity parameter and slope angle on the stability number, $N_{s}=H_{s} / \Delta D_{n}$. Results are shown for the damage $N_{0}=0.5$ after a wave attack of 1,000 waves. The curves are the stability formula that is derived subsequently in the paper. Note that $\cot \theta=1.5$ for the data of Van der Meer (1987b) and De Jong (1996). There are six figures similar to Fig. 4 for different combinations of $N_{0}(=0.0,0.5$, and 1.5) and $N(=1,000$ and 3,000), which are used for the derivation of the formula.

To obtain the formula consistent with those proposed by Van der Meer (1987b) and De Jong (1996), the stability formula is expressed in terms of the following dimensionless variables: $H_{s} / \Delta D_{n}$, $\xi_{z}, \cot \theta$, and $N_{0} / \sqrt{N}$. Two stability formulas are proposed, one for plunging waves and one for surging waves.

For plunging waves on the left side of Fig. 4, the surf similarity parameter, $\xi_{z}$, describes the influence of slope angle and wave steepness on stability. These influences can be described by a power function: $H_{s} / \Delta D_{n}=a_{1} \xi_{z}^{b_{1}}$ with $a_{1}=f\left(N_{0} / \sqrt{N}\right)$. The coefficient $b_{1}$ is determined by a regression analysis for each of the six cases as in Table 2. The average value is approximately -0.4 . Assuming $a_{1}=a_{2} N_{0}^{0.5} / N^{0.25}+a_{3}$, the coefficient $a_{3}$ is determined by a regression analysis as in Table 3 . For the case of $N_{0}=0.0$, the average value is 3.25. Now the stability formula can be written as $H_{s} / \Delta D_{n}=\left(a_{2} N_{0}^{0.5} / N^{0.25}+3.25\right) \xi_{z}^{-0.4}$. To determine the coefficient $a_{2}$ by a regression analysis, both the stability numbers read off form the damage curves for constant damage levels and the measured 
values (i.e., the data in Table 1) are used. In each case, the value of $a_{2}$ is 9.40 and 8.92, respectively, and the average value is 9.2 .

For surging waves on the right side of Fig. 4, different curves are shown for different slope angles. The procedure similar to plunging waves can be followed for surging waves, although the surf similarity parameter does not cover the influence of the slope angle. The influence of the wave steepness is described by $H_{s} / \Delta D_{n}=a_{1} \xi_{z}^{b_{1}}$ with $a_{1}=f\left(N_{0} / \sqrt{N}, \cot \theta\right)$. For surging waves, 18 values of $b_{1}$ were obtained by regression analyses as in Table 4 because different values of $b_{1}$ were determined for different slope angles. The average value of $b_{1}$ is approximately 0.4 . The influence of the slope angle can be described by $H_{s} / \Delta D_{n}=a_{2}(\cot \theta)^{b_{2}} \xi_{z}^{0.4}$ with $a_{2}=f\left(N_{0} / \sqrt{N}\right)$. The coefficient

\begin{tabular}{|c|c|c|c|c|c|c|c|c|c|c|c|}
\hline \multirow{2}{*}{ Case } & \multirow{2}{*}{ Slope } & \multirow{2}{*}{$T_{z}(\mathrm{~s})$} & \multirow{2}{*}{$\begin{array}{c}H_{s} \\
(\mathrm{~cm})\end{array}$} & \multicolumn{2}{|c|}{$N_{0}$} & \multirow{2}{*}{ Case } & \multirow{2}{*}{ Slope } & \multirow{2}{*}{$T_{z}(\mathrm{~s})$} & \multirow{2}{*}{$\begin{array}{c}H_{s} \\
(\mathrm{~cm})\end{array}$} & \multicolumn{2}{|c|}{$N_{0}$} \\
\hline & & & & $N=1000$ & $N=3000$ & & & & & $N=1000$ & $N=3000$ \\
\hline 1 & $1: 4 / 3$ & 1.36 & 9.4 & 0.074 & 0.074 & 31 & $1: 1.5$ & 2.08 & 12.5 & 0.004 & 0.004 \\
\hline 2 & & 1.35 & 12.4 & 0.221 & 0.221 & 32 & & 2.11 & 13.8 & 0.074 & 0.074 \\
\hline 3 & & 1.36 & 14.2 & 0.442 & 0.516 & 33 & & 2.09 & 14.7 & 0.074 & 0.147 \\
\hline 4 & & 1.36 & 15.6 & 1.032 & 1.475 & 34 & & 2.08 & 15.7 & 0.221 & 0.442 \\
\hline 5 & & 1.40 & 17.3 & 1.770 & 3.466 & 35 & & 2.05 & 17.6 & 0.369 & 1.549 \\
\hline 6 & & 1.66 & 8.9 & 0.004 & 0.004 & 36 & & 2.53 & 12.6 & 0.004 & 0.004 \\
\hline 7 & & 1.64 & 12.2 & 0.004 & 0.221 & 37 & & 2.51 & 14.3 & 0.074 & 0.074 \\
\hline 8 & & 1.65 & 13.4 & 0.004 & 0.369 & 38 & & 2.49 & 15.1 & 0.074 & 0.221 \\
\hline 9 & & 1.66 & 14.4 & 0.295 & 0.959 & 39 & & 2.34 & 18.7 & 0.737 & 2.434 \\
\hline 10 & & 1.68 & 16.1 & 0.737 & 5.383 & 40 & & 2.36 & 19.2 & 0.959 & 2.065 \\
\hline 11 & & 2.10 & 12.4 & 0.074 & 0.074 & 41 & $1: 2$ & 1.32 & 8.7 & 0.004 & 0.004 \\
\hline 12 & & 2.13 & 13.6 & 0.074 & 0.147 & 42 & & 1.34 & 11.6 & 0.004 & 0.147 \\
\hline 13 & & 2.14 & 15.9 & 0.295 & 0.516 & 43 & & 1.34 & 13.3 & 0.295 & 0.516 \\
\hline 14 & & 2.16 & 16.9 & 0.885 & 1.917 & 44 & & 1.36 & 14.9 & 0.221 & 0.590 \\
\hline 15 & & 2.15 & 18.7 & 1.991 & 5.162 & 45 & & 1.39 & 16.6 & 0.885 & 2.876 \\
\hline 16 & & 2.57 & 12.3 & 0.074 & 0.074 & 46 & & 1.66 & 8.9 & 0.004 & 0.004 \\
\hline 17 & & 2.53 & 14.0 & 0.369 & 0.442 & 47 & & 1.68 & 11.6 & 0.004 & 0.147 \\
\hline 18 & & 2.52 & 14.8 & 0.074 & 0.369 & 48 & & 1.69 & 12.9 & 0.074 & 0.221 \\
\hline 19 & & 2.36 & 16.9 & 2.212 & 3.614 & 49 & & 1.69 & 13.9 & 0.074 & 0.221 \\
\hline 20 & & 2.31 & 17.7 & 1.475 & 5.752 & 50 & & 1.69 & 15.4 & 0.590 & 1.106 \\
\hline 21 & 1:1.5 & 1.34 & 9.2 & 0.074 & 0.074 & 51 & & 2.08 & 11.9 & 0.004 & 0.004 \\
\hline 22 & & 1.36 & 12.3 & 0.147 & 0.369 & 52 & & 2.11 & 13.2 & 0.004 & 0.004 \\
\hline 23 & & 1.36 & 14.0 & 0.147 & 0.959 & 53 & & 2.10 & 14.0 & 0.004 & 0.147 \\
\hline 24 & & 1.36 & 15.6 & 0.590 & 1.106 & 54 & & 2.09 & 14.9 & 0.295 & 0.442 \\
\hline 25 & & 1.41 & 17.5 & 0.811 & 1.696 & 55 & & 2.06 & 16.8 & 0.442 & 0.885 \\
\hline 26 & & 1.67 & 9.0 & 0.004 & 0.004 & 56 & & 2.50 & 11.7 & 0.074 & 0.147 \\
\hline 27 & & 1.65 & 12.2 & 0.004 & 0.147 & 57 & & 2.49 & 13.4 & 0.004 & 0.004 \\
\hline 28 & & 1.67 & 13.5 & 0.295 & 0.516 & 58 & & 2.48 & 14.2 & 0.147 & 0.369 \\
\hline 29 & & 1.67 & 14.5 & 0.221 & 0.442 & 59 & & 2.37 & 17.0 & 0.664 & 1.032 \\
\hline 30 & & 1.69 & 16.1 & 0.885 & 1.991 & 60 & & 2.31 & 17.2 & 0.590 & 1.180 \\
\hline
\end{tabular}

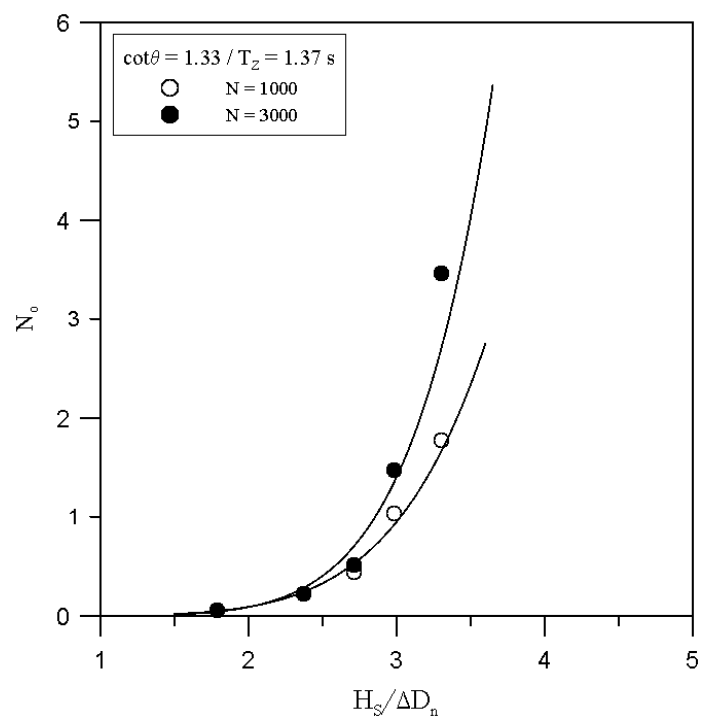

Figure 3. Example of damage curve of $\cot \theta=1.33$ and $T_{z}=1.37 \mathrm{~s}$. 
$b_{2}$ is determined by a regression analysis, and the average value is 0.45. Expressing $a_{2}=a_{3} N_{0}^{0.5} / N^{0.25}+a_{4}$, the coefficient $a_{4}$ is determined by a regression analysis as in Table 5 . For the case of $N_{0}=0.0$, the average value is 0.85 . Finally, following the same procedure as plunging waves, the coefficient $a_{3}$ is determined as 5.0.

Now, the stability formula is proposed as

$$
\frac{H_{s}}{\Delta D_{n}}=\max \left[\left(9.2 \frac{N_{0}^{0.5}}{N^{0.25}}+3.25\right) \xi_{z}^{-0.4},\left(5.0 \frac{N_{0}^{0.5}}{N^{0.25}}+0.85\right)(\cot \theta)^{0.45} \xi_{z}^{0.4}\right]
$$

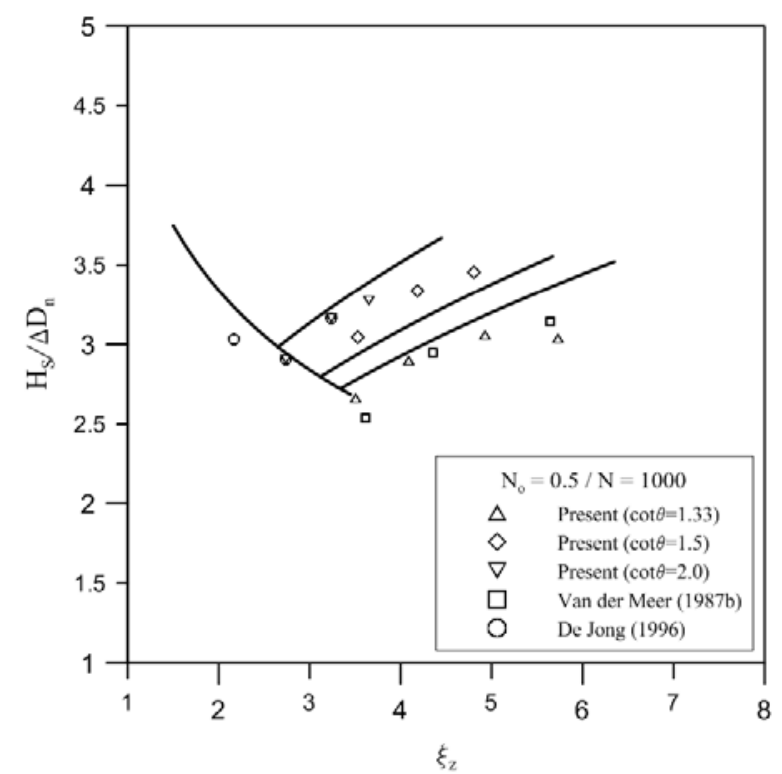

Figure 4. stability number versus surf similarity parameter in the case of $N_{0}=0.5$ and $N=1,000$.

\begin{tabular}{|c|c|c|}
\hline \multicolumn{3}{|c|}{ Table 2. Coefficient $\boldsymbol{b}_{\mathbf{1}}$ for plunging waves. } \\
\hline$N_{0}$ & $b_{1}(N=100)$ & $b_{1}(N=3000)$ \\
\hline 0 & -0.678 & -0.624 \\
0.5 & -0.256 & -0.316 \\
1.5 & -0.373 & -0.184 \\
\hline
\end{tabular}

\begin{tabular}{|c|c|c|}
\hline \multicolumn{3}{|c|}{ Table 3. Coefficient $\boldsymbol{a}_{\mathbf{3}}$ for plunging waves. } \\
\hline$N_{0}$ & $a_{3}(N=1000)$ & $a_{3}(N=3000)$ \\
\hline 0 & 3.359 & 3.160 \\
0.5 & 4.495 & 4.103 \\
1.5 & 5.332 & 4.807 \\
\hline
\end{tabular}

\begin{tabular}{|c|c|c|c|c|c|c|}
\hline Table 4. Coefficient $\boldsymbol{b}_{\mathbf{1}}$ for surging waves. \\
\hline \multirow{2}{*}{$N_{0}$} & \multicolumn{3}{|c|}{$N=1000$} & \multicolumn{3}{c|}{$N=3000$} \\
\cline { 2 - 7 } & 1.33 & 1.5 & 2.0 & 1.33 & 1.5 & 2.0 \\
\hline 0.0 & 0.832 & 0.528 & 0.993 & 0.591 & 0.550 & 0.933 \\
\hline 0.5 & 0.267 & 0.324 & 0.417 & 0.172 & 0.255 & 0.326 \\
\hline 1.5 & 0.087 & 0.132 & 0.122 & 0.160 & 0.319 & 0.329 \\
\hline
\end{tabular}

\begin{tabular}{|c|c|c|}
\hline \multicolumn{3}{|c|}{ Table 5. Coefficient $\boldsymbol{a}_{4}$ for surging waves. } \\
\hline$N_{0}$ & $a_{4}(N=1000)$ & $a_{4}(N=3000)$ \\
\hline 0 & 0.868 & 0.863 \\
0.5 & 1.422 & 1.287 \\
1.5 & 1.685 & 1.458 \\
\hline
\end{tabular}


The preceding equation is basically the same as those of Van der Meer (1988) and De Jong (1996), except that a slope angle term is included in the surging wave formula and the first coefficients (i.e., 9.2 and 5.0) are a little larger.

The transition from plunging waves to surging waves can be calculated using

$$
\xi_{z c}=\left[\frac{9.2 N_{0}^{0.5} / N_{w}^{0.25}+3.25}{\left(5.0 N_{0}^{0.5} / N_{w}^{0.25}+0.85\right)(\cot \theta)^{0.45}}\right]^{1.25}
$$

However, one could compare the formulas and take the one that gives the higher stability number.

De Jong (1996) proposed a formula similar to the plunging wave formula in Eq. (2), but De Jong's formula contains additional terms that take into account the influence of crest elevation and packing density. Borrowing these terms, Eq. (2) can be written as

$$
\frac{H_{s}}{\Delta D_{n}}=\max \left[\begin{array}{l}
\left(9.2 \frac{N_{0}^{0.5}}{N^{0.25}}+3.25 f(\phi)\right) \xi_{z}^{-0.4} f\left(R_{c} / D_{n}\right), \\
\left(5.0 \frac{N_{0}^{0.5}}{N^{0.25}}+0.85 f(\phi)\right)(\cot \theta)^{0.45} \xi_{z}^{0.4} f\left(R_{c} / D_{n}\right)
\end{array}\right]
$$

where

$$
\begin{gathered}
f(\phi)=0.40+0.61 \phi / \phi_{S P M} \\
f\left(R_{c} / D_{n}\right)=1+0.17 \exp \left(-0.61 R_{c} / D_{n}\right)
\end{gathered}
$$

$\phi=$ packing density, the normal value of which is $1.02 ; \phi_{S P M}=$ packing density given in the Shore Protection Manual (U.S. Army 1984), which is 1.04 for Tetrapods; and $R_{c}=$ crest elevation of the breakwater.

\section{COMPARISON OF PROPOSED FORMULA WITH TEST RESULTS}

Fig. 5 compares the measured stability number with the prediction by Eq. (2) for the test results of the present study and other researchers: Van der Meer (1987b), De Jong (1996), and KORDI (Korea Ocean Research \& Development Institute, 2001). Only the data of high-crested breakwaters and normal packing density of De Jong (1996) were used. The data of KORDI was for a breakwater of the slope angle of 1:1.33. The index of agreement is 0.843 . The index of agreement is a statistical parameter proposed by Willmott (1981) as a measure of the degree to which a model's predictions are error-free. It varies between 0 and 1.0, where 1.0 indicates perfect agreement between observation and prediction, and 0 connotes complete disagreement. Fig. 6 compares the measured stability number with the prediction by Eq. (4). The data of low-crested breakwaters and lower packing density of De Jong (1996) were additionally included. The index of agreement is 0.857 , indicating that Eq. (4) including additional terms for crest elevation and packing density is slightly more accurate than Eq. (2). All the over-predicted data points located around the predicted stability number of 5.0 in Figs. 5 and 6 are the cases of $\cot \theta=1.33, H_{s} / \Delta D_{n}>3.0$, and $N=3,000$ except one case in which $N=1,000$. This implies that the developed formula over-predicts the stability number in the case where a steep breakwater is designed for a storm of large wave height and long duration.

The formula (2) is also shown in Fig. 7 together with all the data excluding the data of low-crested breakwaters and lower packing density of De Jong (1996). The plunging wave formula and surging wave formula are shown separately. The transition from plunging to surging waves was calculated with Eq. (3). The plunging wave formula agrees well with the test data. The surging wave formula also agrees well with the test data except for several data of the present test, which correspond to the overpredicted data in Fig. 5. 


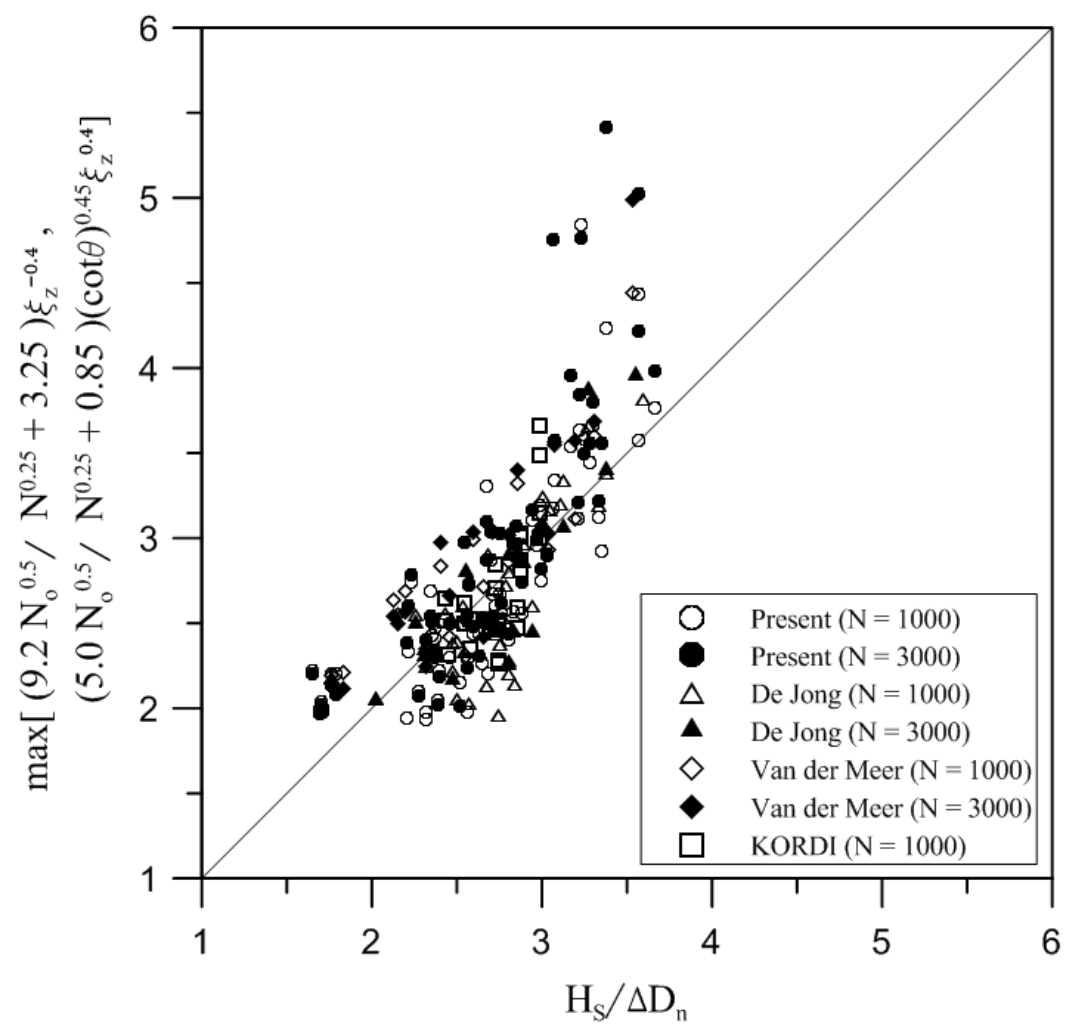

Figure 5. Comparison of stability number between measurement and prediction by Eq. (2) for all available data excluding low-crested breakwaters and lower packing density of De Jong (1996).

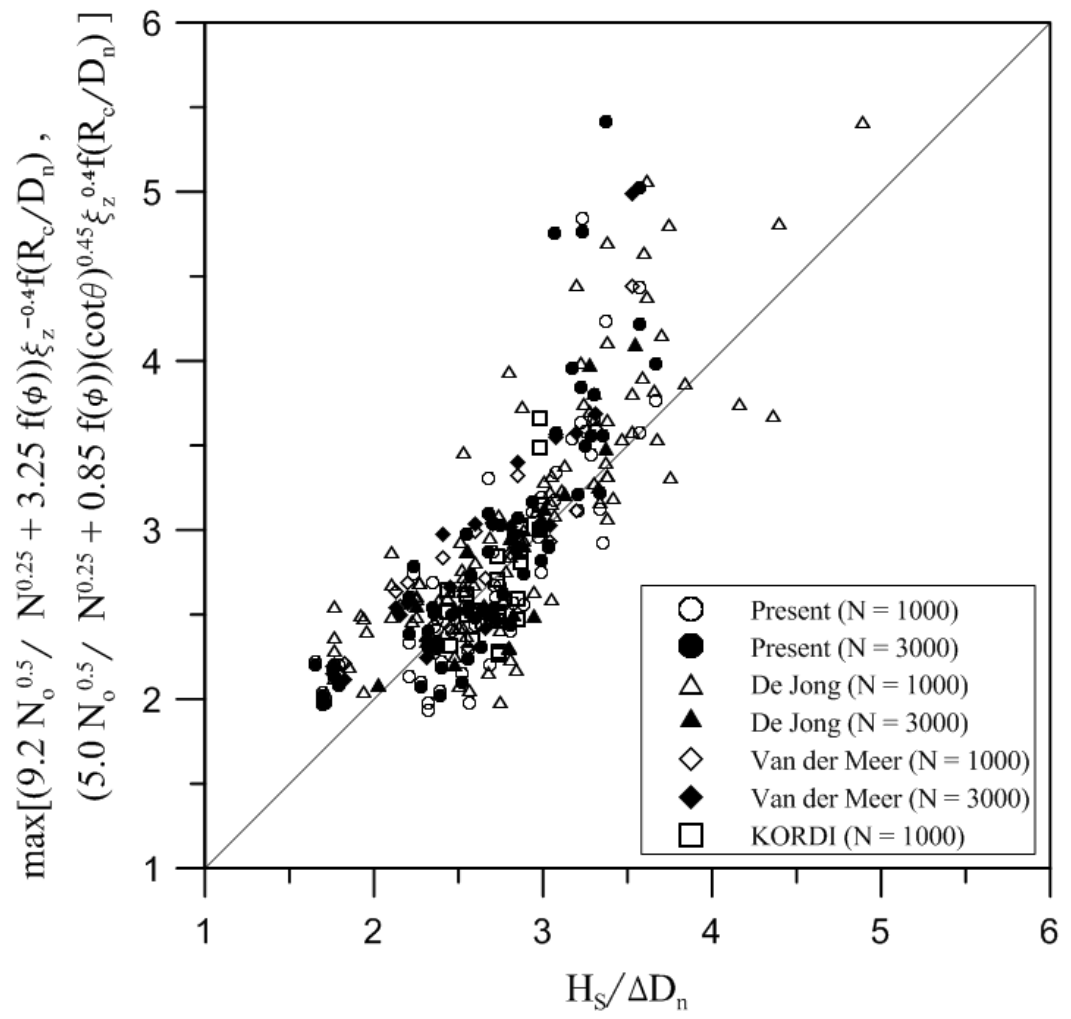

Figure 6. Comparison of stability number between measurement and prediction by Eq. (4) for all available data including low-crested breakwaters and lower packing density of De Jong (1996). 


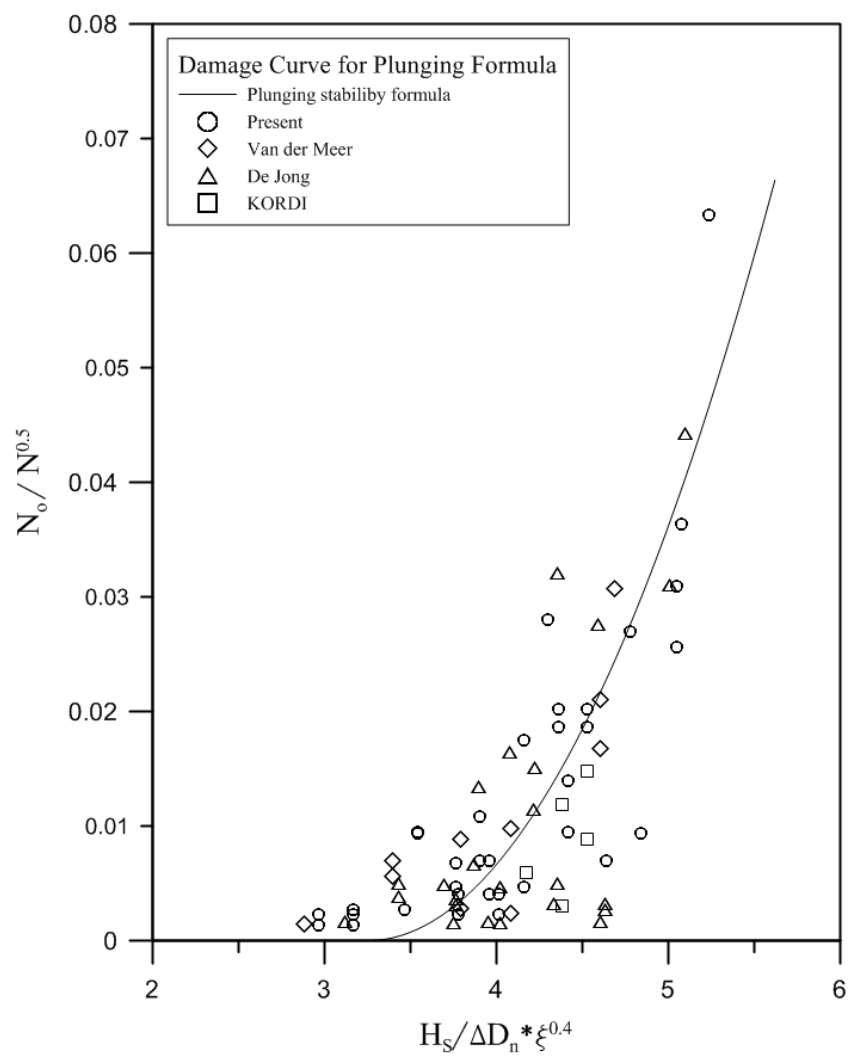

(a)

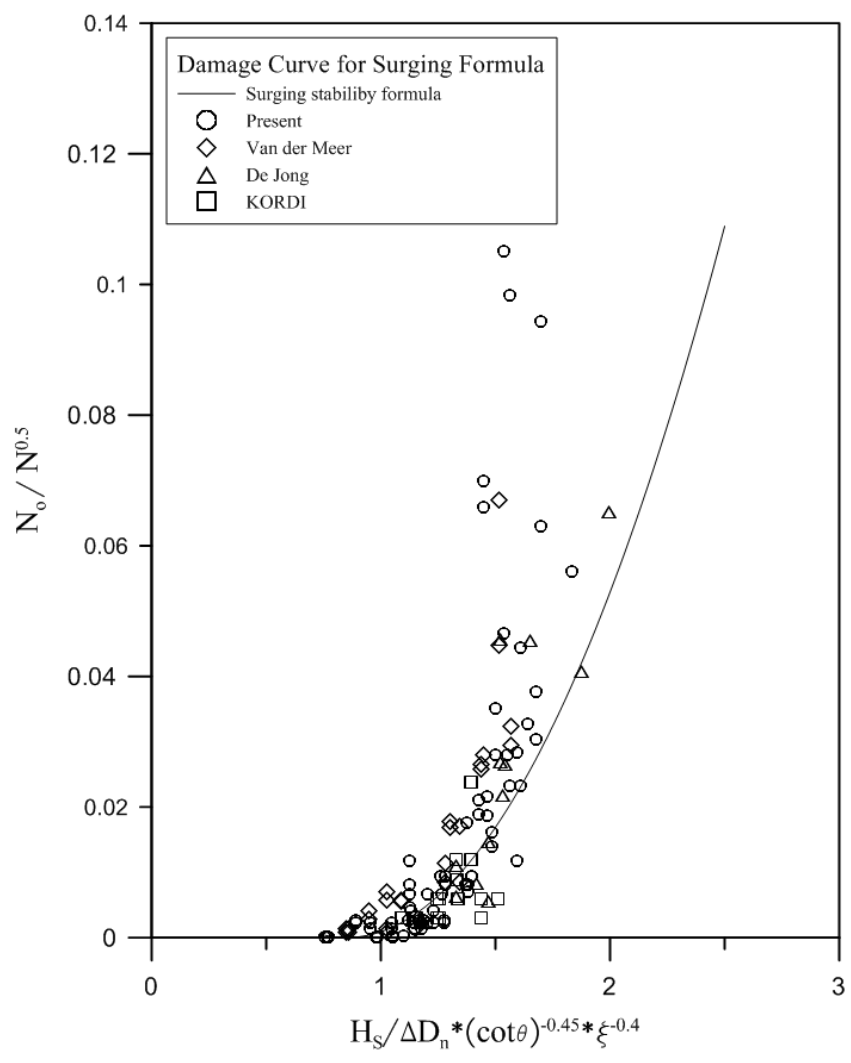

(b)

Figure 7. Comparison of present stability formula against all available data excluding low-crested breakwaters and lower packing density of De Jong (1996): (a) plunging wave formula; (b) surging wave formula. 


\section{UNCERTAINTY OF PROPOSED FORMULA}

Since the 1980s, reliability-based design methods have been developed for breakwater designs, which will be the mainstream of future breakwater designs. Most of the design formulas have been developed based on hydraulic model test results, and the uncertainty of the formula is important in the reliability-based design. The stability formula proposed in this study can be written in the form of a reliability function:

$$
\begin{aligned}
G=\left\{a \Delta D_{n}\left[9.2 N_{0}^{0.5} / N^{0.25}+3.25 f(\phi)\right] f\left(R_{c} / D_{n}\right)-H_{s} \xi_{z}^{0.4}\right. \\
\left.\quad \text { or } a \Delta D_{n}\left[5.0 N_{0}^{0.5} / N^{0.25}+0.85 f(\phi)\right](\cot \theta)^{0.45} f\left(R_{c} / D_{n}\right)-H_{s} \xi_{z}^{-0.4}\right\}=0
\end{aligned}
$$

where $a=$ variable signifying the uncertainty inherent in the formula. The uncertainty of a random variable is best given by a probability distribution. However, because the true distribution is rarely known, it is common to assume a normal distribution and a related coefficient of variation defined as

$$
\sigma^{\prime}=\frac{\sigma}{\mu}
$$

as the measure of the uncertainty, where $\mu$ and $\sigma$ are the mean and standard deviation, respectively. In order to calculate these statistical characteristics of the variable $a$, it was expressed as

$$
\begin{gathered}
a=\frac{H_{s} \xi_{z}^{0.4}}{\Delta D_{n}\left[9.2 \frac{N_{0}^{0.5}}{N^{0.25}}+3.25 f(\phi)\right] f\left(R_{c} / D_{n}\right)} \\
\quad \text { or } \frac{H_{s} \xi_{z}^{-0.4}}{\Delta D_{n}\left[5.0 \frac{N_{0}^{0.5}}{N^{0.25}}+0.85 f(\phi)\right](\cot \theta)^{0.45} f\left(R_{c} / D_{n}\right)}
\end{gathered}
$$

The mean, standard deviation, and coefficient of variation obtained using the data of the present tests are $0.972,0.134$, and 0.138 , respectively. These values are $0.957,0.133$, and 0.139 , respectively, if we include the data of low-crested breakwaters and low packing densities of De Jong (1996). Therefore, the bias and coefficient of variation of the proposed formula are -0.04 and 0.14 , respectively.

\section{CONCLUSION}

We proposed a stability formula for Tetrapods armoring a rubble mound breakwater based on hydraulic model test results of the present and previous studies. The proposed formula was proven to be applicable to breakwaters with various slope angles. It was also shown to be applicable to lowcrested breakwaters and different packing densities if the corresponding terms are incorporated in the formula. The proposed formula over-predicts the stability number in the case where a steep breakwater is designed for a storm of large wave height and long storm duration. The bias and coefficient of variation of the proposed formula are -0.04 and 0.14 , respectively. A study for the influence of the permeability of the filter layer may be necessary in the future.

\section{ACKNOWLEDGMENTS}

This research was supported by the Project for Development of Reliability-Based Design Methods for Port and Harbor Structures sponsored by Korea Ministry of Land, Transport and Marine Affairs. This work was conducted at the Engineering Research Institute of Seoul National University.

\section{REFERENCES}

De Jong, R.J., 1996. Wave transmission at low-crested structure, Stability of Tetrapods at front, crest and rear of a low-crested breakwater. Master thesis, Delft University of Technology, Netherlands.

Goda, Y., 2000. Random seas and design of maritime structures. 2nd Ed., World Scientific, Singapore, $\mathrm{xi}+443 \mathrm{pp}$.

Hanzawa, M., H. Sato, S. Takahashi, K. Shimosako, T. Takayama, K. Tanimoto, 1996. New stability formula for wave-dissipating concrete blocks covering horizontally composite breakwaters. Proc. $25^{\text {th }}$ Int. Conf. Coastal Eng., ASCE, 1665-1678.

Hudson, R.Y., 1959. Laboratory investigation of rubble-mound breakwaters. J. Waterways and Harbors 
Div. 85(WW3): 93-121.

Korea Ocean Research \& Development Institute, 2001. Development of technology for the optimum design of rubble-mound breakwater (I) (in Korean).

Suh, K.D., W.S. Park, B.S. Park, 2001. Separation of incident and reflected waves in wave-current flumes. Coastal Eng. 43: 149-159.

U.S. Army Coastal Engineering Research Center, 1984. Shore protection manual, 4th Ed., U.S. Government Printing Office, Washington, D.C., USA.

Van der Meer, J.W., 1987a. Stability of breakwater armor layers-Design formulae. Coastal Eng. 11: 219-239.

Van der Meer, J.W., 1987b. Stability of rubble mound breakwaters, Stability formula for breakwaters armoured with Tetrapods. Report on Basic Research, H462 Volume II, Delft Hydraulics Laboratory.

Van der Meer, J.W., 1988. Stability of cubes, tetrapods and accropode. In: Design of breakwaters, Thomas Telford, London, 71-80.

Willmott, C.J., 1981. On the validation of models. Phys. Geography 2: 184-194. 